\title{
Competition for water vapour results in suppression of ice formation in mixed-phase clouds
}

\author{
Emma L. Simpson, Paul J. Connolly, and Gordon McFiggans \\ Centre for Atmospheric Science, School of Earth and Environmental Sciences, University of Manchester, \\ Manchester, M13 9PL, UK
}

Correspondence: Gordon McFiggans (g.mcfiggans@manchester.ac.uk)

Received: 19 July 2017 - Discussion started: 17 August 2017

Revised: 5 March 2018 - Accepted: 28 April 2018 - Published: 25 May 2018

\begin{abstract}
The formation of ice in clouds can initiate precipitation and influence a cloud's reflectivity and lifetime, affecting climate to a highly uncertain degree. Nucleation of ice at elevated temperatures requires an ice nucleating particle (INP), which results in so-called heterogeneous freezing. Previously reported measurements for the ability of a particle to nucleate ice have been made in the absence of other aerosol which will act as cloud condensation nuclei $(\mathrm{CCN})$ and are ubiquitous in the atmosphere. Here we show that CCN can "outcompete" INPs for available water vapour thus suppressing ice formation, which has the potential to significantly affect the Earth's radiation budget. The magnitude of this suppression is shown to be dependent on the mass of condensed water required for freezing. Here we show that ice formation in a state-of-the-art cloud parcel model is strongly dependent on the criteria for heterogeneous freezing selected from those previously hypothesised. We have developed an alternative criteria which agrees well with observations from cloud chamber experiments. This study demonstrates the dominant role that competition for water vapour can play in ice formation, highlighting both a need for clarity in the requirements for heterogeneous freezing and for measurements under atmospherically appropriate conditions.
\end{abstract}

\section{Introduction}

A significant fraction, around $20 \%$ of clouds present in our atmosphere are mixed phase in that they contain both liquid and ice particles (Warren et al., 1986, 1988). Such clouds can be very persistent (Morrison et al., 2012). As a result of their widespread coverage, persistent nature and potential to greatly affect modelling results of cloud albedo and thus climate (Sun and Shine, 1994), many observational and modelling studies have been dedicated to researching them (e.g. Verlinde et al., 2007; Hill et al., 2014; Korolev et al., 2003; Shupe et al., 2008). Observations reveal processes within these clouds which we still do not fully understand. For example Morrison et al. (2012) describe the surprising persistence of Arctic mixed-phase clouds and the complex web of interactions between the many physical processes occurring in them that lead to their persistent nature. Even with Morrison et al. (2012)'s insight into the nature of mixed-phase Arctic clouds the ability of climate models to simulate them is lacking (Ovchinnikov et al., 2014). More research is required to fully understand the many ways aerosol composition and size distribution can influence mixed-phase clouds (de Boer et al., 2013). The number of ice crystals and liquid drops present in a cloud strongly depends on the size distribution of aerosols (Twomey, 1991; Andreae and Rosenfeld, 2008). Aerosol particles may grow into liquid drops by the condensation of water vapour in water supersaturated environments. The rate of growth and subsequent "activation" into a cloud droplet of an aerosol particle is determined by its size and chemical composition (Köhler, 1936). There are two types of aerosol particles important for mixed-phase clouds: those that form cloud drops, cloud condensation nuclei $(\mathrm{CCN})$; and those the can form ice crystals, ice nucleating particles (INPs). $\mathrm{CCN}$ are a subset of atmospheric aerosol particles and are ubiquitous in the atmosphere. They are generally made up of soluble compounds allowing them to "activate" into cloud droplets at relatively low supersaturations. INPs are much rarer and are required for freezing at temperatures above the homogeneous freezing level. Common INPs 
are mineral dusts (Murray et al., 2012) which are much less soluble making them less able to compete for water vapour than $\mathrm{CCN}$, as an INP of the same size as a CCN would "activate" into a cloud droplet at a higher supersaturation. This difference in ability to compete for water vapour is potentially significant as it is thought that in mixed-phase clouds the most effective INPs are contained within a liquid drop (Field et al., 2012; Murray et al., 2012).

In this study it is hypothesised, and demonstrated with a cloud parcel model, that the presence of $\mathrm{CCN}$ within a cloud could suppress the formation of ice. The ability of CCN to "outcompete" INPs for water vapour means they could activate into cloud droplets, and therefore provide a sink for water vapour, before the maximum supersaturation within the cloud has reached a level that would allow INPs to grow to an appreciable size. This would result in the INPs without sufficient water on them to be able to freeze, assuming liquid water is a requirement for freezing of the most effective INPs.

In this study we demonstrate that the presence of $\mathrm{CCN}$ can reduce the ice nucleating potential of INPs as a result of the competition for water vapour. The idea that competition for water vapour can result in a reduction of ice formation has been discussed in previous studies. In this particular study we demonstrate that it plays an important role in cloud parcel model simulations of mixed-phase clouds, where the presence of atmospherically relevant $\mathrm{CCN}$ concentrations can significantly reduce ice crystal number concentrations. Levin et al. (2016) observed that competition between aerosol particles limited the targeted relative humidity $(\mathrm{RH})$ within a continuous flow diffusion chamber (CFDC) resulting in inaccurate measurements of INP concentrations. Here we show that the competition for water vapour is not only important in instruments measuring INP number concentrations but also in expansion chambers, which are more atmospherically representative than CFDCs, as well as in simulations using a detailed parcel model. Previous experimental results from the AIDA expansion chamber, which have been used to measure the ice nucleating ability of several different particle types, have corrected for the fact that not all aerosol in chamber will have been able to activate and grow into cloud droplets due to competition for water vapour (Ullrich et al., 2017). This means that their formulation of INP parameterisations do not take competition for water vapour into account as they have been calculated assuming all particles can grow into drops. Therefore the competition effect needs to be addressed within the models which use these ice nucleation parameterisations. Modelling studies such as that by de Boer et al. (2013) do consider the concentration of CCN as having an influence on ice formation in clouds and show that higher concentrations of $\mathrm{CCN}$ can reduce ice number concentration. However their explanation of this effect differs from the one put forward here. de Boer et al. (2013) explain that the reduction in ice formation in their simulations performed with high CCN concentrations is due to a reduction in drop vol- ume, similar to the Twomey effect (Twomey, 1974). The immersion freezing parameterisation that de Boer employ is a function of drop volume and the production of ice particles through immersion freezing decreases as drop volume decreases. In this study we use a different method for calculating the freezing rate that follows Connolly et al. (2009) and Niemand et al. (2012) and is based on the dry surface area of an INP, not the drop volume.

Ice nucleation initiated by an INP can take place via either deposition nucleation or freezing nucleation (Vali et al., 2015). Freezing nucleation requires the presence of liquid water on an INP, and it has also been argued that deposition nucleation has a liquid water transition phase (Vali et al., 2015), however, the exact amount of liquid that needs to be present for ice to form remains unconstrained. In the literature, immersion freezing (which is a type or "mode" of freezing nucleation) has been confined to those particles that have activated in cloud drops (Hoose et al., 2010a; Pruppacher and Klett, 1997) or those drops greater than $2 \mu \mathrm{m}$ in diameter (Paukert and Hoose, 2014). Diehl and Wurzler (2004) use a water activity, similar to the Koop et al. (2000) approach, to calculate the amount of condensed water required to overcome the freezing point depression caused by soluble compounds present as an internal mixture within the INP. However de Boer et al. (2013) found that the freezing point depression due to soluble compounds was not important for large cloud droplets such as those found in stratiform clouds, since droplets are large enough to overcome the effect.

The two main objectives of this work are to provide experimental evidence that our hypothesis is valid and to investigate the sensitivities of the process. Section 2 provides a description of the model used, as well as a detailed description of the freezing criteria we employ in the model. Section 3 details the methodology and results of a series of cloud chamber experiments designed to confirm our hypothesis. Due to constraints of our chamber set-up our experiments probe an area of the parameter space where suppression is not predicted to occur. The results from chamber experiments are also used in a comparison of different freezing criteria and provide a "proof of concept" for our new criteria for freezing. Section 4 provides a demonstration of the suppression effect in model simulations and Sect. 5 explores the sensitivities to the suppression effect. Finally a summary of the overall findings of this work is given in Sect. 6.

\section{Model description}

ACPIM is a detailed bin-resolving cloud parcel model which can be used to model particle activation, droplet growth and ice nucleation within a rising parcel of air under going adiabatic ascent. It can also be used to model particle activation during an expansion experiment in which cloud conditions are generated within a cloud chamber such as the Manchester Ice Cloud Chamber (MICC). When modelling a rising parcel 
of air, water vapour is made available for condensation by prescribing a constant updraft velocity and assuming an atmosphere in hydrostatic balance. For modelling expansions in a chamber, pressure and temperature drop rates provide the source of supersaturation. When modelling specific experiments in a cloud chamber, time dependent pressure and temperature drop rates can be prescribed so that the simulated temperature and pressure profiles fit those that were observed (see Supplement Fig. S5 for an example). An initial relative humidity is defined in the model for both types of simulations.

ACPIM allows the size distribution of any composition of aerosol to be defined using log-normal size distributions. A log-normal size distribution describes the number of aerosol particles per natural logarithm of the bin width, $\frac{\mathrm{d} N}{\mathrm{~d} \ln D_{\mathrm{p}}}$, as is given by the following equation:

$\frac{\mathrm{d} N}{\mathrm{~d} \ln D_{p}}=\frac{N_{\mathrm{ap}}}{\ln \sigma \sqrt{2 \pi}} \exp \left[-\frac{\ln ^{2}\left(\frac{D_{\mathrm{p}}}{d_{\mathrm{m}}}\right)}{2 \ln \sigma^{2}}\right]$,

where $N_{\text {ap }}$ is the total number concentration of aerosol particles, $\ln \sigma$ is the natural logarithm of the geometric standard deviation and $d_{\mathrm{m}}$ is the median diameter (Jacobson, 1999). Any number of aerosol size distributions, or "modes", can be included. Each mode can be made up of any composition. This allows for both internally and externally mixed aerosol size distributions to be represented in the model.

Both subsaturated and supersaturated growth of aerosol particles is included in the model. The point at which an aerosol particle "activates" into a cloud droplet depends on its size and chemical composition and is traditionally defined by Köhler theory (Köhler, 1936; Pruppacher and Klett, 1997). Köhler theory is used to calculate the "critical supersaturation" and "critical droplet radius" required for a given aerosol particle to activate into a cloud droplet. Köhler theory is often approximated by $\kappa$-Köhler theory (Petters and Kreidenweis, 2007) which offers a simplified approach for use in modelling cloud-aerosol interactions. Sorjamaa and Laaksonen (2007) and Kumar et al. (2009) present an activation theory based on the multilayer adsorption of gases which shows promise for the treatment of insoluble particles (Kumar et al., 2011). In all theories the critical supersaturation with respect to water and the critical wet diameter of particle required for activation is dependent on its size and composition. The saturation ratio of water in equilibrium with a particle, for all particles that include some soluble mass in this study, is defined using $\kappa$-Köhler theory following Petters and Kreidenweis (2007), Eq. (2) below. This equation is used to calculate a particle's critical supersaturation with respect to water and its critical wet diameter:

$s=a_{\mathrm{w}} \exp \left(\frac{4 \sigma_{\frac{s}{a}} M_{\mathrm{w}}}{R T \rho_{\mathrm{w}} D}\right)$ where

$a_{\mathrm{w}}=\frac{D^{3}-D_{\mathrm{p}}^{3}}{D^{3}-D_{\mathrm{p}}^{3}(1-\kappa)}$.

In the above-mentioned equations $s$ is the saturation ratio of a particle with dry diameter $D_{\mathrm{p}}, \sigma_{\frac{\mathrm{s}}{\mathrm{a}}}$ is the surface tension of the solution $/$ air interface $=0.072 \mathrm{Jm}^{-2}, M_{\mathrm{W}}$ is the molecular weight of water, $R$ is the universal gas constant, $T$ is temperature, $\rho_{\mathrm{w}}$ is the density of water and $D$ is the particle's wet diameter. Values for the constant $\kappa$ are obtained from measurements for different particle types. Here a value of 0.61 is used for ammonium sulphate (Petters and Kreidenweis, 2007). Insoluble species are given a $\kappa$ value of zero (Petters and Kreidenweis, 2007). The overall $\kappa$ value for an internally mixed aerosol particle is calculated according to the simple mixing rule, Eq. (4) (Petters and Kreidenweis, 2007):

$\kappa=\sum_{i} \varepsilon_{i} \kappa_{i}$

where $\varepsilon_{i}$ is the volume fraction of component $i$ in the particle. In the simulations of chamber experiments K-feldspar particles are given a $1 \%$ soluble mass fraction made up of ammonium sulphate. This results in K-feldspar particles having a $\kappa$ value of 0.0061 in the model. In simulations of an adiabatic parcel, the soluble mass fraction of INPs is either $0,1,25$ or $50 \%$. The growth of drops follows Pruppacher and Klett (1997) and Jacobson (1999) and includes kinetic limitations to growth important for large aerosol particle sizes (Simpson et al., 2014).

For zero soluble fraction $\kappa$-Köhler theory is replaced by FHH adsorption theory following Kumar et al. (2009). FHH adsorption theory may be a more appropriate approach to treating completely insoluble particles (Kumar et al., 2011). FHH theory is similar to $\kappa$-Köhler theory; however, instead of using a single constant $\kappa$ to represent the hygroscopicity of a particle two factors, $A_{\mathrm{FHH}}$ and $B_{\mathrm{FHH}}$, are used to represent molecules adsorbing onto the surface of an insoluble aerosol particle. $A_{\mathrm{FHH}}$ represents the interactive forces of water molecules between the surface and adjacent adsorbate molecules (Hatch et al., 2014). $B_{\mathrm{FHH}}$ characterises the attractive forces between the surface and subsequent adsorbed water layers (Hatch et al., 2014). In ACPIM for an aerosol particle with a soluble fraction of zero, the equation for its equilibrium saturation ratio is calculated using the following equation:

$s=\exp \left(\frac{4 \sigma M_{\mathrm{w}}}{R T \rho_{\mathrm{W}} D}\right) \exp \left(-A_{\mathrm{FHH}} \Theta^{-B_{\mathrm{FHH}}}\right)$,

where $\sigma$ is the surface tension at the particle-gas interface, $M_{\mathrm{w}}$ is the molecular mass of water, $R$ is the universal gas constant, $T$ is temperature, $\rho_{\mathrm{w}}$ is the density of water and $D_{\mathrm{p}}$ is the particle diameter. $\Theta$ is the number of adsorbed layers, defined as the number of adsorbed water molecules divided 
by the number of molecules in a monolayer (Kumar et al., 2009).

Freezing rates of INPs are governed by the $n_{\mathrm{s}}$ parameterisation following Connolly et al. (2009) and Niemand et al. (2012), where $n_{\mathrm{s}}$ is the number concentration of ice active sites per unit surface area of an INP. Here $n_{\mathrm{S}}(T)$ takes the following form for K-feldspar:

$\log _{10}\left(n_{\mathrm{s}}(T)\right)=-a T+b$

where $a=-0.1963, b=60.2118$ and $T$ is temperature in ${ }^{\circ}$ Kelvin. The values for $a$ and $b$ were measured for $\mathrm{K}$ feldspar by Emersic et al. (2015), from the same sample as used in chamber experiments in this study, in the MICC. $n_{\mathrm{s}}(T)$ takes the following form for desert dust:

$n_{\mathrm{S}}(T)=\exp [a(T-273.15)+b]$

where $a=-0.517, b=8.934$ and $T$ is temperature in ${ }^{\circ}$ Kelvin. The values for $a$ and $b$ are from Niemand et al. (2012) and were measured for a variety of natural dust samples. This parameterisation for desert dusts is valid for use at a temperature range between -12 and $-36^{\circ} \mathrm{C}$ (Niemand et al., 2012).

Before an aerosol particle can nucleate ice (in all modes except deposition, although it has been suggested that a liquid transition phase exists in deposition freezing Vali et al., 2015 ) it must be in contact with some liquid water. The minimum mass of water required for ice formation is currently unconstrained. Here we define a "heterogeneous freezing criteria" in order to prevent aerosol particles without any condensed water on them from freezing in the model. In this study three heterogeneous freezing criteria are compared, detailed in Table 1. For all criteria once the criteria has been achieved, freezing is determined by the value of $n_{\mathrm{S}}(T)$ and the surface area of the particle.

There are many contrasting definitions and treatments of the different pathways, or "modes", of heterogeneous freezing found in the literature. Four distinct modes are described: immersion, condensation, contact and deposition. Physical similarities between the different modes can make it difficult for distinctions to be made when modelling heterogeneous freezing. For example contact, immersion and condensation all require liquid water to be present. It is common for two modes of freezing to be treated together in modelling studies. For example Hoose et al. (2008) treat immersion and condensation freezing together, whereas Morrison et al. (2005) argue that condensation and deposition freezing are similar so treat them as the same mode of freezing. Wex et al. (2014) also discuss the lack of clear definitions of the different modes of freezing in the literature. There is uncertainty in the definition of the requirements for immersion or condensation freezing. Walko et al. (1995) and Kärcher and Lohmann (2003) state that condensation freezing requires water saturation; however Ervens and Feingold (2012) describe condensation freezing as occurring below water saturation and immersion as happening above. To avoid confusion and to keep the representation for freezing as physical as possible we do not make a distinction between the different modes of freezing. Instead, defining a "freezing criteria" (see Table 1) ensures that an INP has an amount of water condensed onto it before it is able to freeze. This following is a description of the freezing criteria compared in this study.

Activated only: activation marks the point at which an aerosol particle grows rapidly by the condensation of water vapour, and is often referred to as the point at which an aerosol particle becomes a cloud droplet. Using activation as a criteria for heterogeneous freezing ensures that an INP is immersed within a liquid drop and can therefore only act in the immersion/condensation freezing modes. However the mass of water required for activation is not related to ice formation and INPs which are below activation size may still have sufficient water on them to be able to freeze, as the critical mass of water required for freezing is currently unconstrained.

$\mathrm{RH}>1$ : this criteria for freezing makes certain that almost all aerosol types will have some condensed water on their surface, and therefore ensures that INPs only nucleate ice in the immersion/condensed modes. This criteria for freezing does not provide a specific mass of liquid water required for freezing meaning that an INP may only have a very small mass of water condensed onto it, depending on the particle's hygroscopicity, before it initiates freezing. This criteria also does not take the effects of solutes on the freezing of a solution drop into account.

$M_{\mathrm{cw}}$ : in this study we have developed a new criteria for freezing which is based on the idea that a threshold mass of water is required for freezing. The new criteria defines a threshold mass which is only dependent on particle dry size and is calculated according to the following:

$M_{\mathrm{cw}}=\frac{\alpha_{\mathrm{cw}}}{6} \pi D_{\mathrm{p}}^{3} \rho_{\mathrm{w}}$,

where $M_{\mathrm{cw}}$ is the critical water mass required for freezing, $\alpha_{\mathrm{cw}}$ is a constant, $D_{\mathrm{p}}$ is the particle dry diameter and $\rho_{\mathrm{w}}$ is the density of water. The constant $\alpha_{\mathrm{cw}}$ in this study has a value of 70 . This value gave best agreement between model results for ice number concentration and chamber measurements across six experiments (Fig. 2 and Supplement Fig. S6). Values for $\alpha_{\mathrm{cw}}$ below 10 and above 200 gave poor agreement with chamber results. A size dependent threshold mass of condensed water ensures that the liquid layer on the surface of an INP is a minimum depth before ice nucleation can take place. The surface of an ice nucleus is not typically spherical (Rogers et al., 2001) and will instead have many facets, leading to water condensing into irregular pools on the particle's surface, in which ice can nucleate. This means that the depth of the liquid layer on the INP's surface will not be in direct relation to the particle's surface area nor the drop's volume, and will instead be somewhere in between. We have chosen to calculate the threshold water mass in relation to particle 
Table 1. Table describing the different criteria for heterogeneous freezing used in this study. Once the criteria has been achieved, freezing is determined by the value of $n_{\mathrm{S}}(T)$ and the surface area of the particle.

\begin{tabular}{|c|c|c|}
\hline Label & Description & References \\
\hline Activated only & Only activated drops can freeze & Hoose et al. (2010a); Pruppacher and Klett (1997) \\
\hline$M_{\mathrm{cW}}$ & $\begin{array}{l}\text { Drops must have a threshold mass of } \\
\text { water which is dependent on particle size }\end{array}$ & - \\
\hline $\mathrm{RH}>1$ & At $\mathrm{RH}<1$ drops cannot freeze & Field et al. (2012) \\
\hline
\end{tabular}

volume, as it is not possible to know the exact morphology of the particles. This criteria prevents an INP without any water on it from freezing. The physical idea behind this criteria for freezing is that ice nucleation requires the formation of a ice-like cluster of water molecules to reach a critical size to initiate freezing (Fitzner et al., 2015). This criteria is used to ensure some water mass is present on an INP to allow for the formation of a critical cluster. However, the value of $\alpha_{\mathrm{cw}}$ (used in the calculation of $M_{\mathrm{cw}}$ ) found in this study to give best agreement with observations suggests that the threshold mass of water required for freezing is much larger than that used by the Fitzner et al. (2015) modelling studying on ice nucleation. Further investigation is required in order to establish an exact value for the threshold mass of water required for freezing.

This new criteria for freezing is potentially more physically related to ice formation than the other two criteria described in Table 1 as it is associated with the ratio of particle size to condensed water mass. It is physically reasonable to suggest that a specific ratio of water mass to particle mass is required for freezing. In order to make the new criteria generally applicable to all INP types, further experiments are required to constrain the values of $\alpha_{\mathrm{cw}}$. This work provides a "proof of concept" for the new criteria and a demonstration of the impact heterogeneous freezing criteria can have on the number concentration of ice crystals predicted by cloud microphysical models.

In this study, contact nucleation is not considered, as collisions between particles do not take place in the model set-up used here. Due to the short duration of chamber experiments carried out here as well as the relatively small droplet sizes, collisions between particles in the chamber are unlikely to occur. Contact nucleation is also not considered in adiabatic parcel simulations as contact nucleation is thought to be of secondary importance compared to the other modes of freezing (Phillips et al., 2007).

The full moving bin structure (Jacobson, 1999) was used within the model. This structure was chosen as it is the least numerically diffusive (Jacobson, 1999). It was found that under certain conditions the number concentration of ice crystals was sensitive to the bin structure used, see Supplement Fig. S1. Currently in ACPIM the full moving bin structure does not allow interactions between particles to take place. Here we are only interested in the condensation of wa- ter vapour onto particles and the subsequent nucleation and growth of cloud drops and ice crystals.

\section{Chamber experiments}

\subsection{Description of the chamber and experiments}

MICC is a $10 \mathrm{~m}$ tall and $1 \mathrm{~m}$ in diameter steel tube housed within the University of Manchester. It spans three floors and on each floor it is contained within a cold room where the temperature can be controlled between approximately 20 and $-50^{\circ} \mathrm{C}$. Air can be evacuated from the chamber using two scroll pumps. This evacuation of air causes a cooling within the chamber which generates cloud conditions. The experiments conducted within the current study used the following procedure:

1. Several cleaning cycles were performed in the chamber until the particle concentration was below $10 \mathrm{~cm}^{-3}$, typically around $5 \mathrm{~cm}^{-3}$.

2. INP, in this case K-feldspar, was introduced to the chamber via a dust generator at the top of the chamber. Total aerosol number concentrations were measured at the bottom of the chamber using a condensation particle counter (CPC). A measurement of the aerosol size distribution using a scanning mobility particle sizer 3081 TSI and Grimm 1.109 was also made at this stage, both sampling at the bottom of the chamber. When the concentration measured by the CPC had stabilised the aerosol in the chamber was assumed to be well mixed.

3. Temperature within the chamber was measured by eight thermocouples at locations long its entire length. When all thermocouples measured the same temperature, $\pm 0.5^{\circ} \mathrm{C}$, the chamber was ready for an expansion experiment to begin.

4. The pumps located at the top of the chamber were switched on, to evacuate the chamber, as was a Droplet Measurement Technologies Cloud Droplet Probe (CDP) and a Stratton Park Engineering Company, Inc., Cloud Particle Imager (CPI) Version 1 instrument sampling at the bottom of the chamber. Air was evacuated down to 700 mbar within the chamber. 
5. Air containing ammonium sulphate aerosol was then added to the chamber via a pipe connected to the Manchester Aerosol Chamber (MAC). The pressure in the MICC was then returned to atmospheric pressure by filling from MAC or the clean air system.

6. Steps 3 and 4 of the process were then repeated with the mixture of ammonium sulphate and K-feldspar aerosol.

\subsection{Model set-up and initial conditions for chamber experiments}

For each expansion the temperature profile in the model was fit to the lowest temperature measurements made in the chamber during an expansion; an example is given in Supplement Fig. S5b. It was chosen to fit to the lowest temperature measurements in the chamber as this is likely where most ice would form. An example of the pressure profile in the chamber and the model is given in Supplement Fig. S5a Also shown in Supplement Fig. S5 are the corresponding temperature and pressure profiles from model simulations of those expansion experiments. Both profiles in Supplement Fig. S5 as well as the agreement between measurements and model fit are typical of all expansion experiments presented in Fig. 2 and Supplement Fig. S6.

The initial RH in the chamber was calculated so that water saturation was reached in the model at the same time as was reached in the chamber. Water saturation is assumed to be reached in the chamber when the concentrations of drops (particles $>5 \mu \mathrm{m}$ measured by the CDP) rapidly started to increase, indicating droplet activation. Due to the rapid decrease in temperature at the start of the chamber experiments there is significant uncertainty in the initial RH. This is because the point at which water saturation can be assumed to be reached in the chamber needs to be accurate to within approximately $0.1 \mathrm{~s}$; accuracy is required in order to sufficiently reduce the uncertainty in RH to avoid sensitivity in model results for ice number concentration. To overcome this issue would require RH measurements accurate to $0.1 \%$. Such measurements are not possible in the current chamber setup. Comparison between model and chamber results for ice crystal number concentration are made for a range of initial $\mathrm{RH}$ values. The range of $\mathrm{RH}$ values represents the time period at the beginning of a chamber experiment when the number of drops begins to increase and/or begins to increase more rapidly, indicating the likely period when saturation is reached. Results of model simulations representing chamber experiments shown in Fig. 2 and Supplement Fig. S6 use a value for initial $\mathrm{RH}$ within the uncertainty range that agrees best with observations. Values for initial RH used in the model simulations shown in Fig. 2 and Supplement Fig. S6 range between 63 and $80.5 \%$.

Log-normal size distributions were fitted to aerosol measurements (examples are given in Supplement Figs. S3 and
S4.) and used as input to ACPIM for each chamber expansion experiment.

\subsection{Classification of particle type in chamber simulations}

A CPI was used to make a qualitative assessment of the phase, liquid or ice, of hydrometeors formed during chamber expansions. Due to the small size and high number concentration of the hydrometeors formed in experiments, data from the CPI could not be used quantitatively because of the instrument's small sample volume.

The peaks in concentration of particles with sizes greater than $12 \mu \mathrm{m}$ as measured by the CDP are due to the formation of drops at the beginning of expansions. The CPI measures spherical particles, i.e. drops, early in the expansion, before measuring small irregularly shaped particles, i.e. ice (see Fig. 1a). The drops formed at the beginning of expansions quickly evaporate, as ice crystals begin to form, due to the Wegener-Bergeron-Findeisen (WBF) process. This explains the peak in concentration towards the beginning of expansions, Fig. 2 and also explains why the modelled ice number should be compared with measured particles later in the simulations, since WBF process ensures that ice and liquid water will not coexist.

A size threshold of $12 \mu \mathrm{m}$ was chosen as the distinction between liquid and ice particles. A clear distinction between supercooled drops and ice crystals can be seen in Fig. 1b. Similar experiments carried out in MICC, with the same setup and K-feldspar sample, were carried out by Emersic et al. (2015); they too chose a value close to $12 \mu \mathrm{m}$ to distinguish between ice and liquid.

\subsection{Chamber results}

A total of six expansion experiments were carried out. An example of a typical experiment is given in Fig. 2. The results from all chamber experiments are shown in Supplement Fig. S6. Where CPI data was available dashed red lines represent the sum of liquid droplets and ice crystals initially formed. In experiments where CPI data was not available it can be assumed that drops evaporate at a similar expansion time (around $80 \mathrm{~s}$ ) as in experiments where CPI data is available (Fig. 2), because the experimental conditions are the same. Ammonium sulphate aerosol was included in some of the expansions (Supplement Fig. 3c-f) in order to provide a source of CCN. As hypothesised, no suppression of ice was observed. In the area of the parameter space were our chamber experiments were conducted, i.e. insoluble particles with median mode diameters between $0.35 \mu \mathrm{m}$ and $1.5 \mu \mathrm{m}$ and high updraft velocities similar to the pressure drop rates in the chamber, little suppression was found in model simulations when using either of the two criteria for freezing compared in Sect. 5. 

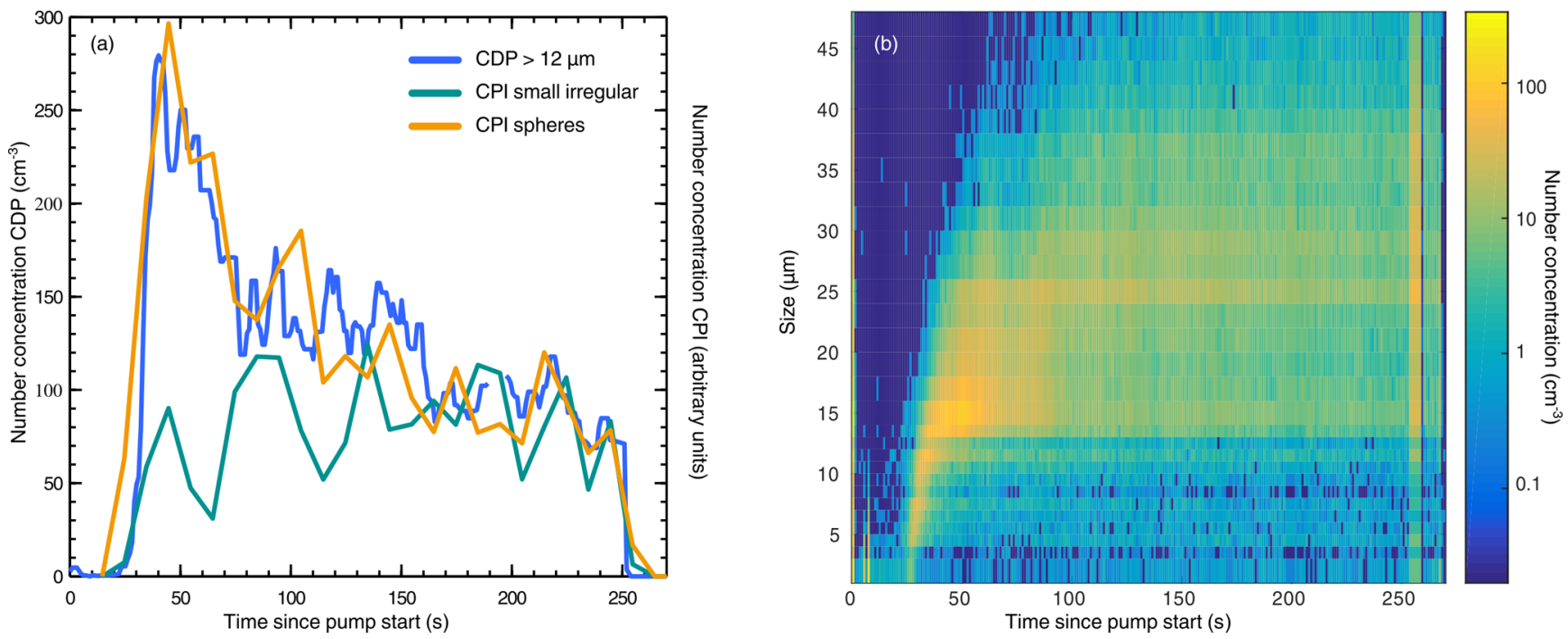

Figure 1. (a) Measurements from the CPI instrument for the two particle habit classifications observed: small irregular (ice), green line; and spheres (drops), orange line. The CDP for particles with sizes greater than $12 \mu \mathrm{m}$ is represented by a blue line. CPI data is shown without units because the data is qualitative. (b) Size distribution of cloud particles measured by the CDP in MICC during an expansion experiment.

Supplement Fig. S6a and b show the number concentration of ice crystals, as measured by the CDP, in the cloud chamber during expansions with only K-feldspar aerosol. Due to the low temperature of the experiments, $-25^{\circ} \mathrm{C}$, many ice crystals are formed resulting in small ice particles and few drops. As described in Sect. 2 collision coalescence is not thought to play a significant role in the growth of droplets in the chamber experiments described here, therefore it is unlikely that there will be many drops in the chamber larger than around $12 \mu \mathrm{m}$. The peak in concentration in Fig. 1a slightly beyond $250 \mathrm{~s}$ is due to ice breaking off the valves connected to the pumps when the pumps are switched off. Frost forms on the chamber walls and the pump valves. When the pumps are switched on and off pieces of frost break off. This can be seen in the measurements as high concentrations of particles at the beginning and end of some experiments. In order to distinguish between liquid and ice particles measured by the CDP, it is assumed all particles above $12 \mu \mathrm{m}$ in diameter are ice, see Fig. 1b. Results from three ACPIM simulations, with the same initial conditions as the chamber expansion, each using a different criteria for heterogeneous freezing (detailed in Table 1) are also shown in Fig. 2 and Supplement Fig. S6.

Within the uncertainty range of initial RH values, both the $M_{\mathrm{cw}}$ and "activated only" criteria for freezing agree well with observation, whereas RH $>1$ criteria greatly overestimate the number of ice crystals, Fig. 2. This is the case across all experiments, with the exception of Supplement Fig. S6b, where all three criteria agree reasonably well.

Although these results are not able to provide evidence for which criteria for freezing are most appropriate, they do show that the new criteria $\left(M_{\mathrm{cw}}\right)$ are as least as good as the existing "activated only" criteria. The results from the cham- ber and corresponding model simulations demonstrate that accurate and precise $\mathrm{RH}$ measurements are required in order to establish what criteria are required for freezing.

In order to investigate the suppression effect in a cloud chamber, temperature and pressure drop rates need to be reduced to values similar to those experienced in the atmosphere, such as those shown in Fig. 3. This allows for a slower rate of increase in RH, which reduces the sensitivity of ice number concentration to the initial RH. These conditions are not currently possible in the MICC set-up where high pressure drops are required in order to generate supersaturated conditions.

\section{Demonstration of the suppression effect}

To demonstrate the suppression of ice formation by the presence of $\mathrm{CCN}$, two simulations were performed with ACPIM: one with INPs and a small number of $\mathrm{CCN}$, and the other with the same number of INPs and a higher number concentration of $\mathrm{CCN}$. The two cases are referred to as "low CCN" and "high CCN", respectively. Results for "low CCN" and "high CCN" cases where the criteria for freezing is "activated only", are shown in Fig. 3a and b. The "low CCN" case contained $1 \mathrm{~L}^{-1} 300 \mathrm{~nm} \mathrm{~K}$-feldspar and $50 \mathrm{~cm}^{-3} 60 \mathrm{~nm}$ ammonium sulphate particles; K-feldspar is the source of INPs and ammonium sulphate particle represent CCN. The "high CCN" case contained the same K-feldspar aerosol and $2000 \mathrm{~cm}^{-3} 200 \mathrm{~nm}$ ammonium sulphate. The inclusion of some CCN particles in the "low CCN" case was necessary in order to be atmospherically relevant, atmospheric aerosol concentrations as low as $1 \mathrm{~L}^{-1}$ are not found and $1 \mathrm{~L}^{-1}$ is considered a typical atmospheric concentration of 


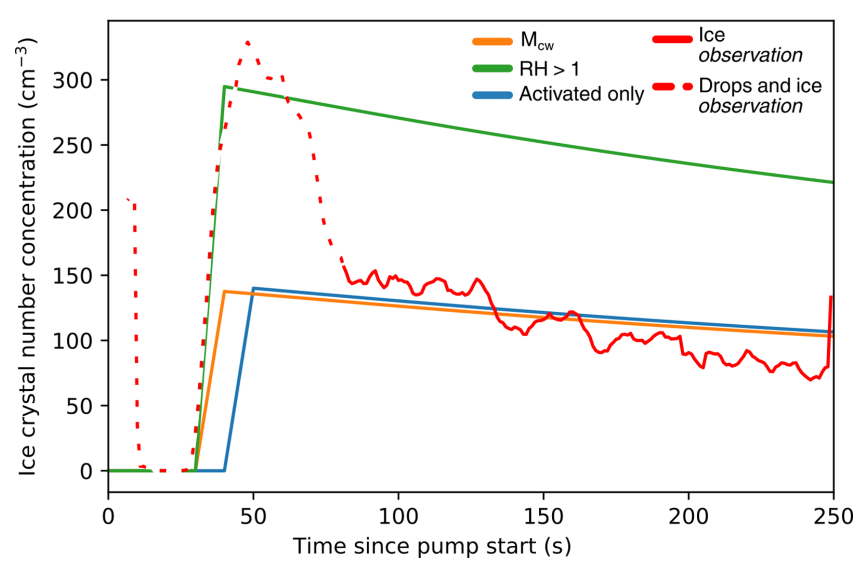

Figure 2. Number concentration of ice crystals in a chamber experiment and model simulations using different criteria for freezing. The solid red line is the number concentration of ice measured in the chamber, the dashed red line represents the sum of liquid droplets and ice crystals initially formed and the other coloured lines are simulated ice number concentrations using different criteria for freezing in the model.

INPs (Murray et al., 2012). Although CCN concentrations as low as $50 \mathrm{~cm}^{-3}$ are still unrealistically low for most of the atmosphere, with the exception of the Arctic Ocean (Mauritsen et al., 2011), it is a situation that maximises the chance for ice formation and at which no suppression is found. The initial conditions for the simulations are the same as those in Table 2 with an updraft velocity of $0.5 \mathrm{~ms}^{-1}$.

Figure 3 a shows a reduced ice number concentration in the "high CCN" case (orange line). This is due to the CCN "outcompeting" the INPs, and providing a sink for water vapour, thus reducing the maximum supersaturation in the cloud below the critical supersaturation of the INPs. The reduction in relative humidity in the "high CCN" case can be seen in Fig. 3b. The liquid water mixing ratio in both cases are similar (see Supplement Fig. S2) showing that the same amount of water is condensing in both cases but onto different particles. The number of $\mathrm{CCN}$ is significantly greater than the number of INPs in the "high CCN" case therefore a greater mass of water is taken up by the $\mathrm{CCN}$ population than the INPs.

The same "high CCN" and "low CCN" cases, with the same initial conditions, were run with different criteria for heterogeneous freezing. Assuming freezing can only occur above water saturation, as in previous studies by de Boer et al. (2010) and as observed by Ansmann et al. (2008), shows no suppression of ice formation. The number concentration of ice in the "high CCN" and "low CCN" cases is the same. This assumption does not depend on the amount of water condensed onto an INP, therefore the ability of an INP to compete for water vapour is irrelevant for ice formation.
Table 2. Initial conditions for parcel model simulations.

\begin{tabular}{ll}
\hline Parameter & Value \\
\hline Pressure & $800 \mathrm{hPa}$ \\
Temperature & $-5^{\circ} \mathrm{C}$ \\
RH & $90 \%$ \\
\hline
\end{tabular}

Table 3. Log-normal parameters for the aerosol in both "low CCN" and "high CCN" simulations. The "high CCN" aerosol are from Van Dingenen et al. (2004) from measurements taken during summer months in the afternoon with only "natural" sources. Mode 1 in "low CCN" is made up of K-feldspar aerosol, (with varying soluble fraction made of ammonium sulphate) and mode 2 is ammonium sulphate.

\begin{tabular}{|c|c|c|c|}
\hline & & high CCN & low $\mathrm{CCN}$ \\
\hline INP & $\begin{array}{l}N\left(\# \mathrm{~cm}^{-3}\right) \\
D(\mathrm{~nm}) \\
\ln \sigma\end{array}$ & $\begin{array}{l}0.001 \\
\text { (variable) } \\
0.5\end{array}$ & $\begin{array}{l}0.001 \\
\text { (variable) } \\
0.5\end{array}$ \\
\hline Mode 2 & $\begin{array}{l}N\left(\# \mathrm{~cm}^{-3}\right) \\
D(\mathrm{~nm}) \\
\ln \sigma\end{array}$ & $\begin{array}{l}185 \\
26 \\
0.44\end{array}$ & $\begin{array}{l}60 \\
60 \\
0.45\end{array}$ \\
\hline Mode 3 & $\begin{array}{l}N\left(\# \mathrm{~cm}^{-3}\right) \\
D(\mathrm{~nm}) \\
\ln \sigma\end{array}$ & $\begin{array}{l}1364 \\
85 \\
0.47\end{array}$ & $\begin{array}{l}- \\
- \\
-\end{array}$ \\
\hline Mode 4 & $\begin{array}{l}N\left(\# \mathrm{~cm}^{-3}\right) \\
D(\mathrm{~nm}) \\
\ln \sigma\end{array}$ & $\begin{array}{l}276 \\
246 \\
0.32\end{array}$ & $\begin{array}{l}- \\
- \\
-\end{array}$ \\
\hline
\end{tabular}

\section{Sensitivities of the suppression effect}

An investigation to find the conditions under which the suppression effect is most significant was conducted. The number concentration of ice crystals in several pairs of simulations of a rising parcel of air, with initial conditions detailed in Tables 2 and 3 were compared: one with INPs and a small number of CCN present, "low CCN"; the other with more $\mathrm{CCN}$ and the same number of INPs, "high CCN" simulations. A small amount of $\mathrm{CCN}$ were included in the "low CCN" cases as total atmospheric aerosol concentrations as low as $0.001 \mathrm{~cm}^{-3}$ do not occur. Ice number concentrations were taken at the simulation time that corresponded to a temperature $-30^{\circ} \mathrm{C}$ for results shown in Fig. 4. The results from these simulations of the percentage difference in ice number concentration between the "low CCN" simulations and "high CCN" simulations are shown in Fig. 4 for INPs with four different soluble fractions: $-0,1,25$ and $50 \%$.

Values for $A_{\mathrm{FHH}}$ and $B_{\mathrm{FHH}}$ are determined experimentally and are unique to different compounds (Kumar et al., 2009). The values for the $A_{\mathrm{FHH}}$ and $B_{\mathrm{FHH}}$ constants used here are 2.25 and 1.8, respectively, and are from measurements made by Kumar et al. (2011) on a variety of dust samples. 


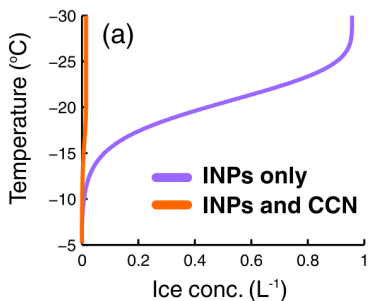

(c)

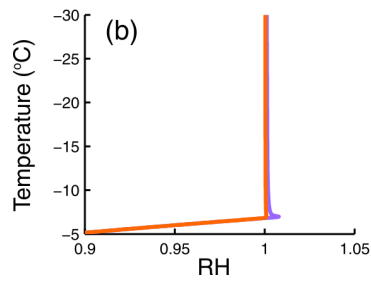

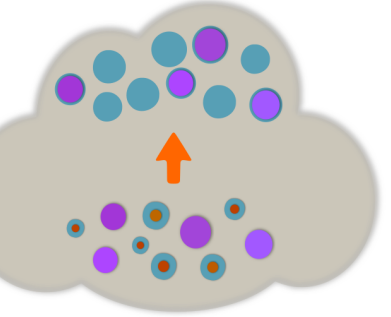

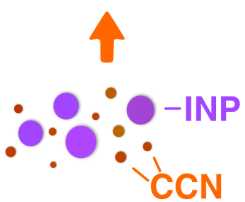

(d)
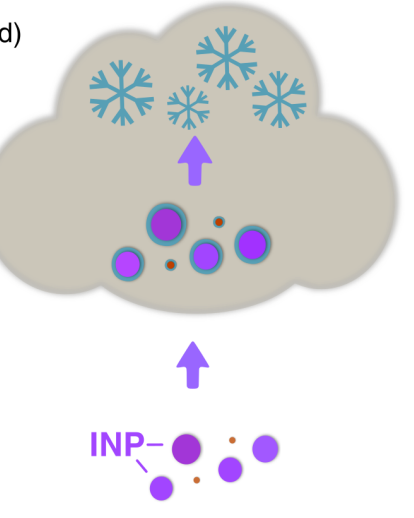

Figure 3. A schematic diagram demonstrating the suppression of ice formation caused by the presence of CCN. (c) The INPs and CCN (high $\mathrm{CCN}$ ) case where water vapour condenses onto the $\mathrm{CCN}$ in preference to the INPs preventing them from activating and freezing. (d) The "low CCN" case where, without the CCN, the max supersaturation ((a) purple line) can rise high enough for INPs to activate and then freeze. (a) Relative humidity and (b) ice concentration with decreasing temperature for the two cases. The "low CCN" case (purple lines) contained $1 \mathrm{~L}^{-1} 300 \mathrm{~nm} \mathrm{~K}$-feldspar and $50 \mathrm{~cm}^{-3} 60 \mathrm{~nm}$ ammonium sulphate particles. The "high CCN" case (orange lines) contained $1 \mathrm{~L}^{-1} 300 \mathrm{~nm}$ $\mathrm{K}$-feldspar and $2000 \mathrm{~cm}^{-3} 200 \mathrm{~nm}$ ammonium sulphate. Initial conditions for the two simulations are the same as those detailed in Table 2 . An updraft velocity of $0.5 \mathrm{~ms}^{-1}$ was used in both cases. The criteria for heterogeneous freezing was "activated only".
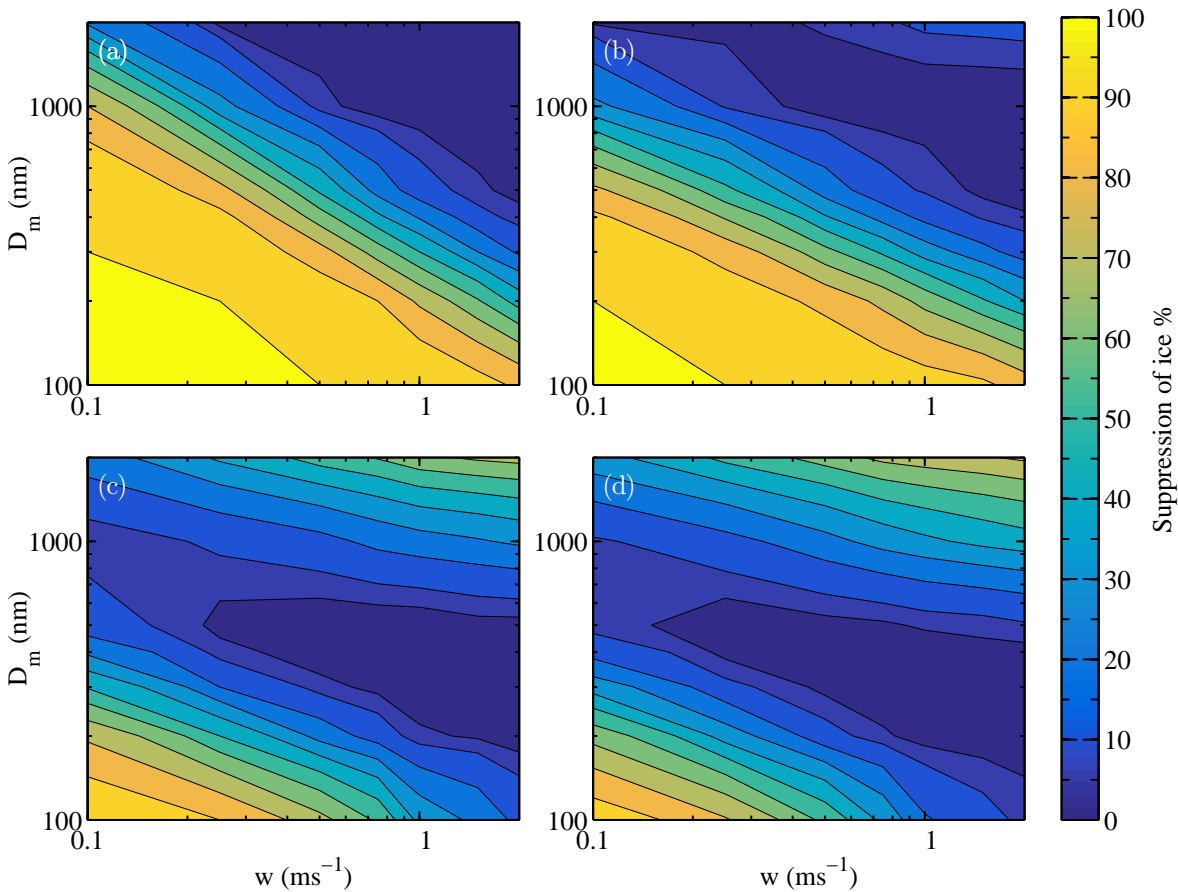

Figure 4. Results from 196 pairs of "low CCN" and "high CCN" model simulations with initial conditions as detailed in Tables 2 and 3 . For each of the four soluble fractions of INP the updraft velocity ranged between 0.1 and $2 \mathrm{~ms}^{-1}$ and the diameter of the INP varied between 100 and $2000 \mathrm{~nm}$. The ice crystal number concentration in every simulation was taken at $-30^{\circ} \mathrm{C}$. Contours show the percentage less ice that formed in the "high CCN" case compared to the "low CCN" case. The criteria for heterogeneous freezing in these results is that only activated drops can freeze.

Figure 4 highlights the locations in the parameter space where most suppression occurs when the criteria for heterogeneous freezing is "activated only". A value of $100 \%$ sup- pression indicates no ice formation in the "high $\mathrm{CCN}$ " case compared to between 0.03 and $0.7 \mathrm{~L}^{-1}$ ice crystal number concentration in the "low CCN" case. Figure 4a shows re- 
sults for the percentage suppression of ice due to the presence of CCN when the INPs are completely insoluble and their growth and activation into cloud drops is calculated using FHH adsorption theory. Most suppression occurs at low updraft velocities and small median diameters of INP.

Figure $4 \mathrm{~b}$ shows similar results to Fig. $4 \mathrm{a}$, however, for INPs that have a $1 \%$ soluble fraction. In this case the growth and activation into cloud drops is calculated according to $\kappa$ Köhler theory. The soluble fraction is made up of ammonium sulphate. There is a general trend towards less suppression in panel (b) compared to panel (a) (Fig. 4). This indicates that the slightly soluble INPs are better able to compete for water vapour. In the top right hand corner of panel $b$, which displays high updraft and large INP diameters, there is a slight suppression. This feature becomes more prominent at higher soluble fractions as can be seen in panels (c) and (d) of Fig. 4.

Most suppression occurs at low updraft velocities and small INP diameters. This is to be expected because smaller diameter particles require higher supersaturations in order to activate into cloud droplets and then freeze. At low updraft velocities the maximum supersaturation generated in the cloud will be low so that only particles with low critical supersaturations, i.e. hygroscopic particles, such as $\mathrm{CCN}$, can activate. The activation of CCN into cloud drops creates a sink for water vapour keeping the maximum supersaturation in the cloud below that of the INPs, thus preventing them for activating and freezing.

Figure 4 reveals two regimes that result in the suppression of ice formation due to the presence of CCN. The first regime, regime 1 , is when INPs are in competition with $\mathrm{CCN}$ for available water vapour (bottom left of panels in Fig. 4). The CCN are better able to compete than the INPs and thus grow and activate into cloud drops creating a sink for water vapour and thus preventing the maximum supersaturation in the parcel from rising to a level that which would allow the INPs to activate. As only activated drops can freeze in this case, ice formation is suppressed since INPs are prevented from activating. In the second regime, regime 2 (towards the top right hand corners of panels $\mathrm{c}$ and d in Fig. 4) INPs have a significant soluble fraction that allows them to act as giant $\mathrm{CCN}$ at large diameters, towards $2 \mu \mathrm{m}$. This results in a reduction of ice formation in "high CCN" simulations and, to a lesser extent, in "low CCN" simulations. The reason for this reduction in ice formation is that there is increased competition for water vapour due to the INPs acting as giant $\mathrm{CCN}$. Another contribution to the suppression effect in regime 2 is the higher updraft velocities. The time taken to reach $-30^{\circ} \mathrm{C}$ in simulations with high updrafts is less than in simulations with low updrafts. The growth rate of large aerosol particles is less than that of small aerosol particles due to kinetic limitations to growth (Chuang et al., 1997). This means that with less time, fewer INPs are able to grow sufficiently in order for freezing to occur. The ice crystal number concentration in "low CCN" cases at high updrafts and large sizes with INPs that include a soluble fraction, are reduced compared to equivalent simulations at lower updrafts. This highlights that kinetic limitations to growth and the competition between the INPs for water vapour exists in the absence of CCN. The introduction of $\mathrm{CCN}$ in the "high CCN" case further reduces the ice crystal number concentration by reducing the supersaturation in the parcel and thus the number of INPs that can activate and freeze.

The suppression at high updraft velocities and large INP median diameters is enhanced when the ice crystal concentrations between the "low CCN" and "high CCN" cases are compared at higher temperatures. Supplement Figs. S9 and S10 are similar to Fig. 4, however the ice crystal number concentrations are compared at -15 and $-20^{\circ} \mathrm{C}$ respectively. The greater suppression seen with increasing temperature is due the kinetic limitations to growth of large particles.

At warmer temperatures the number concentration of ice in the low CCN cases is less than at colder temperatures. However in high $\mathrm{CCN}$ cases the number concentration of ice at $-15,-20$ and $-30{ }^{\circ} \mathrm{C}$ is similar. INPs in the "low $\mathrm{CCN}$ " cases have a greater potential to grow sufficiently in order to freeze, as a relatively high supersaturation is maintained for a larger proportion of the simulation time due to limited competition for water vapour. In "high CCN" simulations the supersaturation is rapidly reduced, meaning that the growth period of INPs is limited. The period of time in which INPs are able to significantly grow occurs before approximately $-15^{\circ} \mathrm{C}$ in "high CCN" cases therefore the ice number concentration is similar at $-15,-20$ and $-30^{\circ} \mathrm{C}$. However in the "low CCN" cases a relatively high supersaturation is maintained beyond $-15^{\circ} \mathrm{C}$ allowing INPs to continue growing at lower temperatures and the ice crystal number concentration to continue to increase. Thus ice crystal concentrations in the "low CCN" cases are significantly higher at lower temperatures.

The magnitudes of the suppression of ice formation for insoluble and slightly soluble INPs (Fig. 4a and b and Fig. 5) is very similar. This is because the threshold masses of condensed water required for the freezing of particles with very low to no soluble fractions, defined by the two criteria, "activated only" and $M_{\mathrm{cw}}$, are very similar. At higher INP soluble fractions (panels $\mathrm{c}$ and d) the mass of water required for a particle to activate increases. However the mass required to reach $M_{\mathrm{cw}}$ remains the same as it is for low soluble fractions, as the calculation of $M_{\mathrm{cw}}$ does not depend on particle composition. This results is little to no suppression in Fig. $5 \mathrm{c}$ and $\mathrm{d}$ for the $M_{\mathrm{cw}}$ criteria. For particles with higher soluble fractions the mass of water required for activation is similar for particle sizes below about 800 nm, see Supplement Fig. S15.

Simulations, the results of which are shown in Fig. 4 and Fig. 5, were repeated with a representation of desert dust instead of K-Feldspar. The results from these simulations are presented in Supplement Figs. S13 and S14 and are very similar to the results found for K-feldspar except with slightly more suppression seen in regime 2 for INPs with some soluble fraction (panels b-d). The ice nucleating ability 

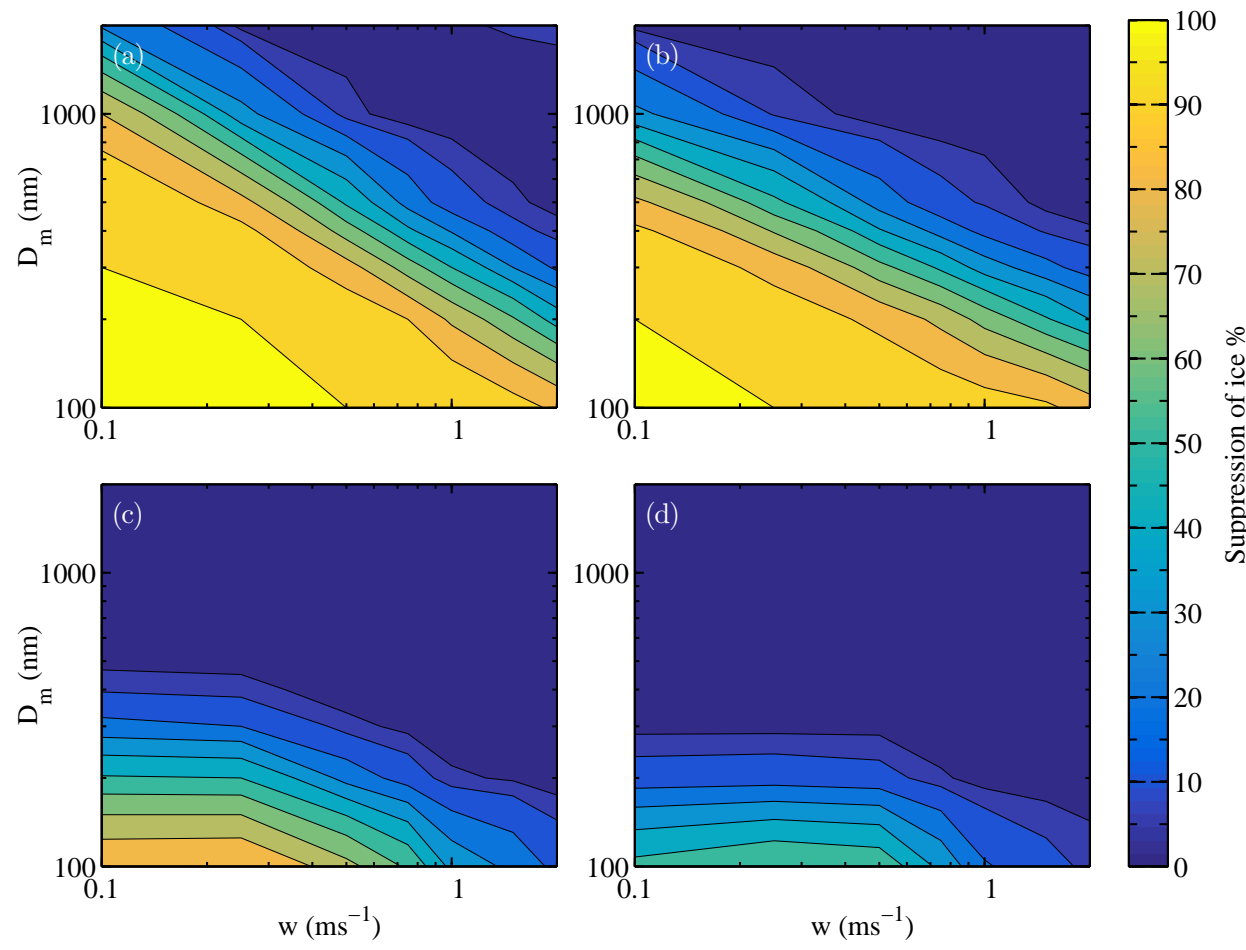

Figure 5. Same as Fig. 4 however the criteria for heterogeneous freezing in these results is $M_{\mathrm{cw}}$.

of desert dust follows Niemand et al. (2012). The representation of desert dust used here is less ice active compared to K-feldspar.

The effect of soluble material in solution on freezing is implicitly taken into account by the "activated only" criteria for freezing through $\kappa$ in Eq. (3). Higher values of $\kappa$, which represent a higher soluble fraction of INP, result in a lower $a_{\mathrm{w}}$ compared to a particle with the same dry and wet size but lower soluble fraction. Therefore a particle with a high $\kappa$ value will require more condensed water in order to reach activation than a particle with a low $\kappa$ value.

The $M_{\mathrm{cw}}$ criteria for freezing does not take the effect of soluble material on freezing into account. There is no dependence in the equation for $M_{\mathrm{cw}}$, Eq. (8), on particle type, only particle size. However, as is the case with all other freezing criteria, once the criteria has been reached, the ability of a particle to freeze is determined by $n_{\mathrm{S}}$ which is dependent on the mass fraction of ice active compounds. The higher the soluble mass fraction of an INP the lower $n_{\mathrm{s}}$ will be, therefore the less likely an INP will be to freeze.

In order to explicitly assess the effect of soluble species on the freezing of a drop, a parameterisation following Diehl and Wurzler (2004) was included in the model which includes the effect of solution on freezing. This parameterisation uses Koop et al. (2000) parameterisation for homogeneous freezing which describes that the freezing of a solution drop is only dependent on $a_{\mathrm{w}}$, and that homogeneous freezing begins when the freezing rate, $J$, is larger than $1 \mathrm{~cm}^{-3} \mathrm{~s}^{-1}$ (Pruppacher and Klett, 1997). Supplement Fig. S7 shows the fit used here for the freezing temperature of a solution, $T_{\mathrm{fs}}$ when $\log J=0 \mathrm{~cm}^{-3} \mathrm{~s}^{-1}$. The effect of soluble compounds, present in a drop, on freezing is taken into account by calculating the freezing point depression as follows:

$T_{\mathrm{dep}}=T+\Delta T$,

where $\Delta T$ is the difference between $T_{\mathrm{fs}}$ and the freezing temperature when $a_{\mathrm{w}}=1$, i.e. when no solute is present. $T_{\mathrm{dep}}$ is then used to calculate the number of ice active sites present in a drop using $n_{\mathrm{s}}\left(T_{\mathrm{dep}}\right)$. For $a_{\mathrm{w}}<1 T_{\text {dep }}$ will be higher than the actual temperature at the given model time step therefore $n_{\mathrm{s}}$ will be lower when solutes are present. Less suppression of ice formation was found when the effect of a freezing point depression caused by the presence of soluble compounds was taken into account in the model compared to results for $\mathbf{M}_{\mathrm{cw}}$ (Supplement Fig. S8). The maximum suppression seen in Supplement Fig. S8 is around $20 \%$ which occurs in the lowest soluble fraction case, $1 \%$ soluble fraction. Our results show that when there is competition for water vapour from $\mathrm{CCN}$ particles, INPs with a soluble component are able to compete effectively for water vapour due to their increased kappa value and grow sufficiently dilute that there is no freezing point depression. 


\section{Conclusions}

The competition for water vapour between INPs and CCN can result in the suppression of ice formation if it is assumed that only activated drops can freeze. Such an assumption has been made in the literature for "immersion mode" freezing (Hoose et al., 2010b; Pruppacher and Klett, 1997). The suppression effect is greatest in low updraft conditions where the INPs have small diameters and are mostly insoluble. Two "regimes" of the suppression effect can be seen in the results of our sensitivity study. The first occurs at low updrafts and small INP diameters. Here INPs are in competition with $\mathrm{CCN}$ for available water vapour which results in them not receiving enough water to be able to activate and freeze. The second regime occurs at higher updrafts and INPs with a significant soluble fraction and large median diameter. Here the INPs act as giant $\mathrm{CCN}$ resulting in them being in competition with themselves as well as the $\mathrm{CCN}$ for water vapour.

Significantly less suppression is seen, and is confined to INPs with low soluble fractions and diameters less than $400 \mathrm{~nm}$, if the criteria for heterogeneous freezing is that an INP must receive a threshold mass of condensed water and that mass is small compared to its activated size. Such a criterion, as well as an INP must be activated into a cloud droplet and were used to accurately simulate ice formation in cloud chamber experiments. Although both criteria show agreement in chamber experiments, when applied to simulations of a parcel of air in the atmosphere results can vary significantly. This indicates the need for further investigation into the criteria for heterogeneous freezing, as we have shown that the fraction of frozen ice nuclei in simulations where $\mathrm{CCN}$ are present varies significantly depending on the freezing criteria applied in the model; in some cases it can be the difference between ice formation and no ice formation.

Experiments in this study were not able to show the suppression effect because the pressure drop rate in the chamber is too high, corresponding to high updraft velocities where model simulations show the effect to be minimal. In order to observe the suppression effect experimental conditions need to simulate atmospheric conditions with low updraft velocities, $\sim<2 \mathrm{~ms}^{-1}$.

Further work will include an investigation into how this suppression effect may manifest its self in large-scale weather and climate models.

Data availability. Access to data and model code can be obtained by contacting the corresponding author.

The Supplement related to this article is available online at https://doi.org/10.5194/acp-18-7237-2018-supplement.
Competing interests. The authors declare that there are no competing interests.

Acknowledgements. This work was funded by a NERC studentship, grant number NE/L501591/1. Funding for cloud chamber work was provided under CCN-Vol, grant number NE/L007827/1. Emma L. Simpson would like to thank James Dorsey, Angela Buchholz and Will Hesson for their help and support during the cloud chamber experiments. Paul J. Connolly acknowledges funding from the European Union's 7th Framework Programme BACCHUS (FP7/2007-2013) under grant agreement number 603445. The MAC received funding from the European Union's Framework 7 EUROCHAMP2 Network of Infrastructures, and MAC and MICC both currently receive funding from the Horizon 2020 research and innovation programme through the EUROCHAMP-2020 Infrastructure Activity under grant agreement no. 730997.

Edited by: Xiaohong Liu

Reviewed by: two anonymous referees

\section{References}

Andreae, M. O. and Rosenfeld, D.: Aerosol-cloud-precipitation interactions. Part 1. The nature and sources of cloud-active aerosols, Earth-Sci. Rev., 89, 13-41, 2008.

Ansmann, A., Tesche, M., Althausen, D., Müller, D., Seifert, P., Freudenthaler, V., Heese, B., Wiegner, M., Pisani, G., Knippertz, P., and Dubovik, O.: Influence of Saharan dust on cloud glaciation in southern Morocco during the Saharan Mineral Dust Experiment, J. Geophys. Res., 113, https://doi.org/10.1029/2007JD008785, 2008.

Chuang, P., Y., Charlson, R. J., and Seinfeld, J. H.: Kinetic limitations on droplet formation in clouds, Nature, 390, 594-596, 1997.

Connolly, P. J., Möhler, O., Field, P. R., Saathoff, H., Burgess, R., Choularton, T., and Gallagher, M.: Studies of heterogeneous freezing by three different desert dust samples, Atmos. Chem. Phys., 9, 2805-2824, https://doi.org/10.5194/acp-9-2805-2009, 2009.

de Boer, G., Hasino, T., and Tripoli, G. J.: Ice nucleation through immersion freezing in mixed-phase stratiform clouds: Theory and numerical simulations, Atmos. Res., 96, 315-324, 2010.

de Boer, G., Hashino, T., Tripoli, G. J., and Eloranta, E. W.: A numerical study of aerosol influence on mixed-phase stratiform clouds through modulation of the liquid phase, Atmos. Chem. Phys., 13, 1733-1749, https://doi.org/10.5194/acp-131733-2013, 2013.

Diehl, K. and Wurzler, S.: Heterogeneous drop freezing in the immersion mode: Model calculations considering soluble and insoluble particles in the drops, J. Atmos. Sci., 61, 2063-2072, 2004.

Emersic, C., Connolly, P. J., Boult, S., Campana, M., and Li, Z.: Investigating the discrepancy between wet-suspensionand dry-dispersion-derived ice nucleation efficiency of mineral particles, Atmos. Chem. Phys., 15, 11311-11326, https://doi.org/10.5194/acp-15-11311-2015, 2015.

Ervens, B. and Feingold, G.: On the representation of immersion and condensation freezing in cloud models using differ- 
ent nucleation schemes, Atmos. Chem. Phys., 12, 5807-5826, https://doi.org/10.5194/acp-12-5807-2012, 2012.

Field, P. R., Heymsfield, A. J., Shipway, B. J., DeMott, P. J., Pratt, K. A., Rogers, D. C., Stith, J., and Prather, K. A.: Ice in clouds experiment-layer clouds. Part II: Testing characteristics of heterogeneous ice formation in lee waves clouds, J. Atmos. Sci., 69, 1066-1070, 2012.

Fitzner, M., Sosso, G. C., Cox, S. J., and Michaelides, A.: The many faces of heterogeneous ice nucleation: interplay between surface morphology and hydrophobicity, J. Am. Chem. Soc., 137, 13658-13669, https://doi.org/10.1021/jacs.5b08748, 2015.

Hatch, C. D., Greenway, A. L., Christie, M. J., and Baltrusaitis, J.: Water adsorption constained Frenkel-Halsey-Hill adsorption activation theory: Montmorillonite and illite, Atmos. Environ., 87, 26-33, 2014.

Hill, A. A., Field, P. R., Furtado, K., Korolev, A., and Shipway, B. J.: Mixed-phase clouds in a turdulent environment. Part 1: Largeeddy simulation experiments, Q. J. Roy. Meteor. Soc., 140, 855869,2014

Hoose, C., Lohmann, U., Erdin, R., and Tegen, I.: The global influence of dust mineralogical composition on heterogeneous ice nucleation in mixed-phase clouds, Environ. Res. Lett., 3, https://doi.org/10.1088/1748-9326/3/2/025003, 2008.

Hoose, C., Kristjansson, J. E., Chen, J., and Hazra, A.: A classicaltheory-based parameterisation of heterogeneous ice nucleation by mineral dust, soot, and biological particles in a global climate model, J. Atmos. Sci., 67, 2483-2503, 2010a.

Hoose, C., Kristjansson, J. E., Chen, J., and Hazra, A.: A classicaltheory-based parameterisation of heterogeneous ice nucleation by mineral dust, soot, and biological particles in a global climate model, J. Atmos. Sci., 67, 2483-2503, 2010b.

Jacobson, M. Z.: Fundamentals of atmospheric modelling, Cambridge University Press, 409-455, 1999.

Kärcher, B. and Lohmann, U.: A parameterization of cirrus cloud formation: Heterogeneous freezing, J. Geophys. Res., 108, 4402, https://doi.org/10.1029/2002JD003220, 2003.

Köhler, H.: The nucleus in and the growth of hygroscopic droplets, Trans. Faraday Soc., 32, 1152-1161, 1936.

Koop, T., Luo, B., Tsias, A., and Peter, T.: Water activity as the determinant for homogeneous ice nucleation in aqueous solutions, Nature, 406, 611-614, 2000.

Korolev, A., Isaac, G. A., Cober, S. G., Strapp, J. W., and Hallett, J.: Microphysical characterization of mixed-phase clouds, Q. J. Roy. Meteor. Soc., 129, 39-65, 2003.

Kumar, P., Sokolik, I. N., and Nenes, A.: Parameterization of cloud droplet formation for global and regional models: including adsorption activation from insoluble CCN, Atmos. Chem. Phys., 9, 2517-2532, https://doi.org/10.5194/acp-9-2517-2009, 2009.

Kumar, P., Sokolik, I. N., and Nenes, A.: Measurements of cloud condensation nuclei activity and droplet activation kinetics of fresh unprocessed regional dust samples and minerals, Atmos. Chem. Phys., 11, 3527-3541, https://doi.org/10.5194/acp-113527-2011, 2011.

Levin, E. J. T., McMeeking, G. R., DeMott, P. J., Mccluskey, C. S., Carrico, C. M., Nakao, S., Jayarathne, T., Stone, E. A., Stockwell, C. E., Yokelson, R. J., and Kreidenweis, S. M.: Icenucleating particle emissions from biomass combustion and the potential importance of soot aerosol, J. Geophys. Res.-Atmos., 121, 5888-5903, 2016.
Mauritsen, T., Sedlar, J., Tjernström, M., Leck, C., Martin, M., Shupe, M., Sjogren, S., Sierau, B., Persson, P. O. G., Brooks, I. M., and Swietlicki, E.: An Arctic CCN-limited cloud-aerosol regime, Atmos. Chem. Phys., 11, 165-173, https://doi.org/10.5194/acp-11-165-2011, 2011.

Morrison, H., Shupe, M. D., Pinto, J. O., and Curry, J. A.: Possible roles of ice nucleation mode and ice nuclei depletion in the extended lifetime of Arctic mixed-phase clouds, Geophys. Res. Lett., 32, 18801, https://doi.org/10.1029/2005GL023614, 2005.

Morrison, H., de Boer, G., Feingold, G., Harrington, J., Shupe, M. D., and Sulia, K.: Resilience of persistent Arctic mixed-phase clouds, Nat. Geosci., 5, 11-17, 2012.

Murray, B. J., O’Sullivan, D., Atkinson, J. D., and Webb, M. E.: Ice nucleation by particles immersed in supercooled cloud droplets, Chem. Soc. Rev., 41, 6519-6554, 2012.

Niemand, M., Möhler, O., Vogel, B., Vogel, H., Hoose, C., Connolly, P., Klein, H., Bingemer, H., DeMott, P., Skrotzki, J., and Leisner: A particle-surface-area parameterisation of immersion freezing on desert dust particles, J. Atmos. Sci., 69, 3077-3092, 2012.

Ovchinnikov, M., Ackerman, A. S., Avramov, A., Cheng, A., Fan, J., Fridlind, A. M., Ghan, S., Harrington, J., Hoose, C., Korolev, A., McFarquhar, G., M., Morrison, H., Paukert, M., Savre, J., Shipway, B. J., Shupe, M. D., Solomon, A., and Sulia, K.: Intercomparison of large-eddy simulations of Arctic mixed-phase clouds: Importance of ice size distribution assumptions, J. Adv. Model. Earth Syst., 6, 233-248, 2014.

Paukert, M. and Hoose, C.: Modeling immersion freezing with aerosol-dependent prognostic ice nuclei in Artice mixed-phase clouds, J. Geophys. Res.-Atmos., 119, 9073-9092, 2014.

Petters, M. D. and Kreidenweis, S. M.: A single parameter representation of hygroscopic growth and cloud condensation nucleus activity, Atmos. Chem. Phys., 7, 1961-1971, https://doi.org/10.5194/acp-7-1961-2007, 2007.

Phillips, V. T. J., Donner, L. J., and garner, S. T.: Nucleation Processes in Deep Convection Simulated by a Cloud-SystemResolving Model with Double-Moment Bulk Microphysics, J. Atmos. Sci., 64, 738-761, 2007.

Pruppacher, H. R. and Klett, J. D.: Microphysics of clouds and precipitation 2nd ed, Kluwer Academic Publishers, Boston, 173512, 1997.

Rogers, D. C., DeMott, P. J., and Kreidenweis, S. M.: Airborne measurements of tropospheric ice-nucleating aerosol particles in the Arctic spring, J. Geophys. Res., 106, 15053-15063, 2001.

Shupe, M. D., daniel, J. S., de Boer, G., Eloranta, E. W., Kollias, P., Long, C. N., Luke, E. P., Turner, D. D., and Verlinde, J.: A focus on mixed-phase clouds: the status of ground-based observational methods, B. Am. Meteor. Soc., https://doi.org/10.1175/2008BAMS2378.1, 1549-1562, 2008.

Simpson, E., Connolly, P., and McFiggans, G.: An investigation into the performance of four cloud droplet activation parameterisations, Geosci. Model Dev., 7, 1535-1542, https://doi.org/10.5194/gmd-7-1535-2014, 2014.

Sorjamaa, R. and Laaksonen, A.: The effect of $\mathrm{H}_{2} \mathrm{O}$ adsorption on cloud drop activation of insoluble particles: a theoretical framework, Atmos. Chem. Phys., 7, 6175-6180, https://doi.org/10.5194/acp-7-6175-2007, 2007. 
Sun, Z. and Shine, K.: Studies of the radiative properties of ice and mixed-phase clouds, Q. J. Roy. Meteor. Soc., 120, 111-137, 1994.

Twomey, S.: Pollution and the planetary albedo, Atmos. Environ., 8, 1251-1256, 1974.

Twomey, S.: Aerosols, clouds and radiation, Atmos. Environ., 25A, 2435-2442, 1991.

Ullrich, R., Hoose, C., Mohler, O., Niemand, M., Wagner, R., Hohler, K., Hiranuma, N., Saathoff, H., and Leisner, T.: A new ice nucleation active site parameterisation for desert dust and soot, J. Atmos. Sci., 74, 699-717, https://doi.org/10.1175/JASD-16-0074.1, 2017.

Vali, G., DeMott, P. J., Mohler, O., and Whale, T. F.: Technical Note: A proposal for ice nucleation terminology, Atmos. Chem. Phys., 15, 10263-10270, https://doi.org/10.5194/acp-15-102632015, 2015.

Van Dingenen, R., Raes, F., Putaud, J., Baltensperger, U., Charron, A., Facchini, M., Decessari, S., Fuzzi, S., Gehrig, R., Hansson, H.-C., Harrision, R., Hüglin, C., Jones, A. M., Laj, P., Lorbeer, G., Maenhaut, W., Palmgren, F., Querol, X., Rodrguez, S., Schneider, J., Brink, H., Tunved, P., Torseth, K., Wehner, B., Weingartner, E., Wiedensohler, A., and Wahlin, P.: A European aerosol phenomenology-1: physical characteristics of particulate matter at kerbside, urban, rural and background sites in Europe, Atmos. Environ., 38, 2561-2577, 2004.
Verlinde, J., Harrington, J. Y., McFarquahar, G. M., Yannuzzi, V. T., Avramov, A., Greenberg, S., Johnson, N., Zhang, G., Poelloy, M. R., Mather, J. H., Turner, D. D., Eloranta, E. W., Zak, B. D., Prenni, A. J., Daniel, J. S., Kok, G. L., Tobin, D. C., Holz, R., Sassen, K., Spangenberg, D., Minnis, P., Tooman, T. P., Ivey, M. D., Richardson, S. J., Bahrmann, C. P., Shupe, M., deMott, P. J., Heymsfield, A. J., and Schofield, R.: The mixed-phase arctic cloud experiment, B. Am. Meteorol. Soc., 205-221, 2007.

Walko, R. L., Cotton, W. R., Meyers, M. P., and Harrington, J. Y.: New RAMS cloud microphysics parameterisation Part I: the single-moment scheme, Atmos. Res., 38, 29-62, 1995.

Warren, S. G., Hahn, C. J., London, J., Chervin, R. M., and Jenne, R. L.: Global distribution of total cloud cover and cloud type amounts over land, NCAR Technical Notes, 273, 1986.

Warren, S. G., Hahn, C. J., London, J., Chervin, R. M., and Jenne, R. L.: Global distribution of total cloud cover and cloud type amounts over ocean, NCAR Technical Notes, 317, 1988.

Wex, H., DeMott, P. J., Tobo, Y., Hartmann, S., Rösch, M., Clauss, T., Tomsche, L., Niedermeier, D., and Stratmann, F.: Kaolinite particles as ice nuclei: learning from the use of different kaolinite samples and different coatings, Atmos. Chem. Phys., 14, 55295546, https://doi.org/10.5194/acp-14-5529-2014, 2014. 